\title{
INDICATOR FOR PROJECT OPTIMIZATION WITH THE COST- TIME INVESTMENT CRITERION
}

\author{
Borut Buchmeister, Iztok Palcic \\ University of Maribor, Faculty of Mechanical Engineering, Smetanova 17, SI-2000 Maribor, Slovenia
}

\begin{abstract}
Companies have to look permanently for new strategies and tools to improve processes, decrease cost and increase productivity and efficiency. Projects are one of the basic means by which a company achieves its competitive advantage and successful business operations. Among all success criteria, factors and frameworks, quality, costs and time remain the most important ones. They are also interdependent, especially in the field of project scheduling, which is our major research field.

In the paper, we deal with a case study of a selected simple test project. We are introducing cost-time profiles to the project area. We want to find out the impact of non-critical activities execution periods to project's cost-time investment. Using slack for delay of such activities brings essential total improvements. The results show that the differences are significant, bringing a potential for project optimization. Additionally we compare the cases with the special indicator - coefficient of investment.
\end{abstract}

Keywords: project; slack time; cost-time investment; cost-time profile, coefficient of investment; activity
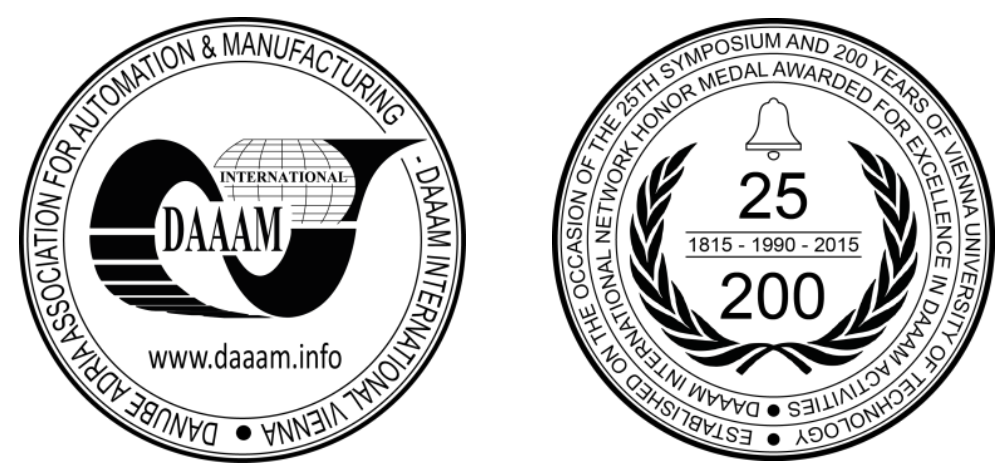

This Publication has to be referred as: Buchmeister, B[orut] \& Palcic, I[ztok] (2016). Indicator for Project Optimization with the Cost-Time Investment Criterion, Proceedings of the 26th DAAAM International Symposium, pp.0012-0017, B. Katalinic (Ed.), Published by DAAAM International, ISBN 978-3-902734-07-5, ISSN 1726-9679, Vienna, Austria DOI:10.2507/26th.daaam.proceedings.002 


\section{Introduction}

Time and cost reduction is imperative for every company, so monitoring and control of project cost over the time can be a good base for improvements. Time is money and using less consumable in manufacturing could be a good strategy for money-making and money savings could also be achieved by preventing waste [1].

Project management has become one of the most popular tools for worldwide organisations to improve internal operations and respond rapidly to external opportunities [2]. The project critical path sets the project duration, where the focus is on critical activities. However, non-critical activities also play a vital role in project success as their start and finish times directly influence the capital invested in the project. We have simulated different scenarios of project schedules based on non-critical activities delay and applied Cost-Time Profile concept. We present how focus on CostTime Investment could influence our decision on project scheduling process.

Project is a sequence of unique, complex and connected activities that have one goal or purpose and that must be completed by a specific time, within budget, and according to specification [3]. Projects and their activities are constrained by limitations on budget, schedule and personnel (resources) availability [4].

If the project fulfils the performance, time and costs criteria, it is said to be efficient. The relationship between all three criteria emphasizes the fact that we have to find an appropriate balance between them [5]. It is practically impossible to improve one of these criteria without influencing the other two. Project success may even be extended further to include the accomplishment of more strategic objectives and benefits, including impacts on markets and competitors, value-adding optimization, supply chains, business development or expansion, and ability to react to future opportunities or challenges [6,7].

\begin{tabular}{|ll|}
\hline Nomenclature \\
$C$ & accumulated total cost \\
$C I$ & coefficient of investment \\
$C T I$ & cost-time investment \\
$t$ & project duration time \\
\hline
\end{tabular}

\section{Cost-time profile in project management}

A Cost-Time Profile (CTP) is a simple graphical tool, which depicts the accumulated costs that have been expended during the execution of a project at every time unit during the process. This way of presenting the information follows the use of resources through time, from the moment the execution begins until the company recovers those invested resources through the sale of the product. The area under the CTP is called the Cost-Time Investment (CTI), because it presents how much money has been tied up in the manufacturing process and for how long before being recovered through sales [8]. Fig. 1 gives a simple illustration of a CTP.

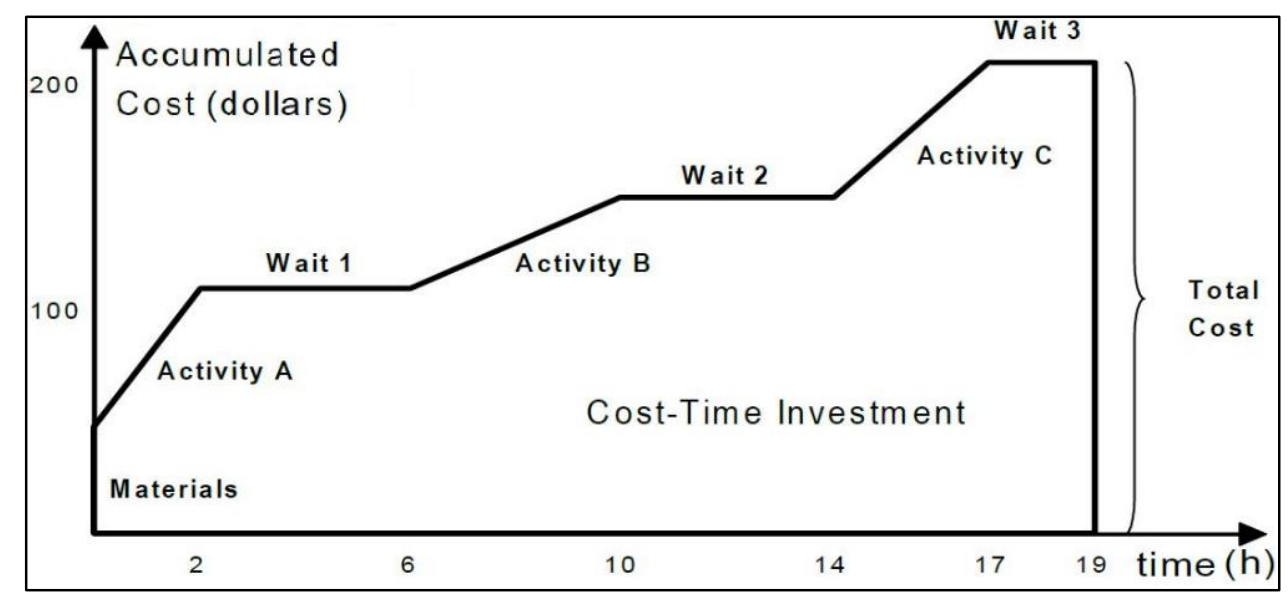

Fig. 1. Example of Cost-Time Profile and Cost-Time Investment [9]

There are several important parts on a CTP. Activities are the parts that actively add cost. They are represented by positive slope lines. Some activities require materials to be performed. The assumption is that the materials arrive right at the beginning of the activity and all at once, therefore a vertical line (instantaneous accumulation of cost) represents them. Waits are moments when nothing that adds cost is actively happening. Total cost is the height of the curve at the end of the project. It represents the total accumulated cost of the project. However, this total cost does not reflect the effect of time on the investment. CTI is the area under the CTP curve, and it represents how much money and for how long has it been invested in the project [10]. 
Direct costs include labour, materials, and any other costs directly related to the project activities [11]. The Direct cost is obtained as follows:

Direct Cost $=$ Total Cost $+($ Cost-Time Investment $\times$ Cost-of-Money-Rate $)$

CTP does not consider indirect costs because it is truly hard to assign these costs directly to activities or to product parts. In project management, it is reasonable to assume that all resources, people and equipment that take part in the project are directly and completely assignable to the project. Nevertheless, CTP and CTI could be applied in other fields too, for example in manufacturing scheduling optimization $[12,13]$, and fit into the context of lean production $[11,14,15,16,17,18,19]$.

\section{Case study}

The presented research focuses on investigation of the applicability of the CTI criterion at project implementation phase. For that purpose, we have used a simple case of a project with 8 activities and tested different scenarios. With the Cost-Time Profile simulation of different activities schedules and CTI simulation, the comparison and appropriate conclusions with some specific guidelines are enabled. Basic information about the project is presented in Table 1.

\begin{tabular}{ccc}
\hline Activity & $\begin{array}{c}\text { Estimated } \\
\text { duration }(h)\end{array}$ & Predecessors \\
\hline A & 40 & - \\
B & 62 & - \\
C & 55 & - \\
D & 90 & A \\
E & 30 & A, B \\
F & 75 & C \\
G & 40 & D, E \\
H & 30 & F, G \\
\hline \multicolumn{4}{c}{} \\
\hline
\end{tabular}

Table 1. Project information

Activities A, B and C can begin immediately. All other activities have one or more predecessors, which must be completed to enable their start. For constructing the activity network we have applied Activity-on-Arrow (AOA) logic (the arrow represents the activity). Network analysis has been done with the Critical Path Method (CPM). The results are given in Fig. 2.

As a result, we got four critical activities and four non-critical activities (which represent $53 \%$ of total project activities time). All non-critical activities have some slack (each 39 hours on average, which means $20 \%$ of project duration); each activity may be delayed from its early start without delaying the finish of the project. To study the impact of possible delay of non-critical activities on the CTI we have simulated three scenarios:

- Non-critical activities are performed as soon as possible (case 1),

- Non-critical activities start in the middle of the early start and the late start time interval (case 2),

- $\quad$ Non-critical activities are performed as late as possible (case 3).

Activity periods for non-critical activities and for all three cases are collected in Table 2.

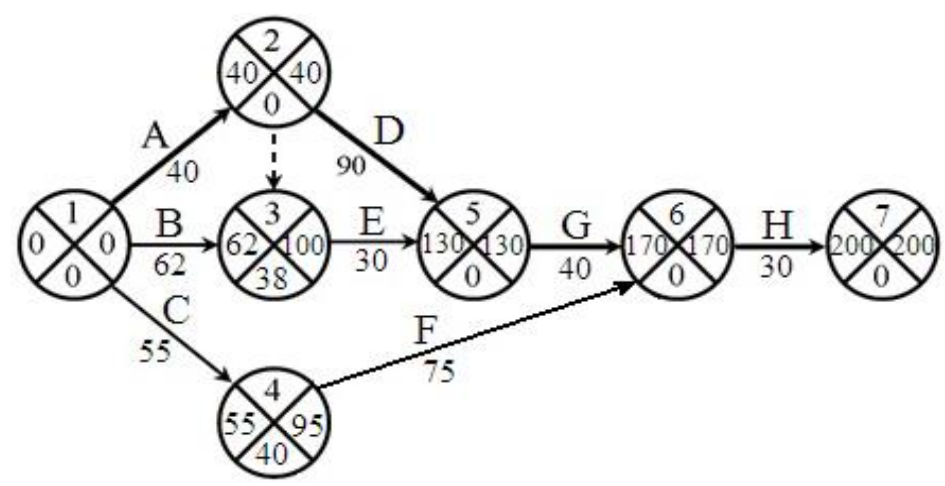

Project duration: $200 \mathrm{~h}$ (= 25 working days $=1.1$ month)

Critical events: $1,2,5,6,7$

Critical path: A-D-G-H

Fig. 2. Project network diagram for given project data 


\begin{tabular}{ccccccc}
\hline \multirow{2}{*}{ Activity } & \multicolumn{2}{c}{ Case 1 } & \multicolumn{2}{c}{ Case 2 } & \multicolumn{2}{c}{ Case 3 } \\
\cline { 2 - 7 } & Start $(h)$ & $\begin{array}{c}\text { Finish } \\
(h)\end{array}$ & Start $(h)$ & $\begin{array}{c}\text { Finish } \\
(h)\end{array}$ & $\begin{array}{c}\text { Start } \\
(h)\end{array}$ & $\begin{array}{c}\text { Finish } \\
(h)\end{array}$ \\
\hline B & 0 & 62 & 19 & 81 & 38 & 100 \\
\hline C & 0 & 55 & 20 & 75 & 40 & 95 \\
\hline E & 62 & 92 & 81 & 111 & 100 & 130 \\
\hline F & 55 & 130 & 75 & 150 & 95 & 170 \\
\hline
\end{tabular}

Table 2. Non-critical activities' intervals (scheduled starting and finishing times)

Other important project data and necessary simplifications, constraints or presumptions are:

- Number of working days per year is 250 ;

- Annual cost of capital rate is $10 \%$;

- Materials and tools are purchased using the JIT principle;

- Materials and tools cost are known, for B - totally 6000 EUR, for D - totally 12000 EUR;

- Hourly rates (in EUR) for the whole group of employees (between 1 and 10 persons in a group) engaged for the activities, A: 45, B: 175, C: 28, D: 16, E: 38, F: 50, G: 50, H: 35;

- Other cost components, possible to be used in the software (maintenance cost, resources' price, resources' life, overhead rate, profit rate etc.) are neglected and taken as zero;

- All costs are entered in 102 EUR (for better visibility in graphic presentation, collected for all cases - see Fig. 3).

For the calculations and simulation of cost-time profiles and CTI we used Cost Time Profiler software, developed in 2006 at Virginia Tech (in the Center for High Performance Manufacturing) for use on the Microsoft.NET Framework 2.0 platform.

\subsection{Case 1}

Non-critical activities start at earliest possible start times. The CTI is calculated for all activities and for all considered costs (6379780€.h). Project total cost: 41570 EUR (the same in all studied cases).

\subsection{Case 2}

Non-critical activities start at time, which is delayed for $50 \%$ of slack (after the earliest possible start time). CTI = $5932170 €$.h.

\subsection{Case 3}

Non-critical activities start at latest possible start times giving the smallest CTI $=5484560 €$.h.

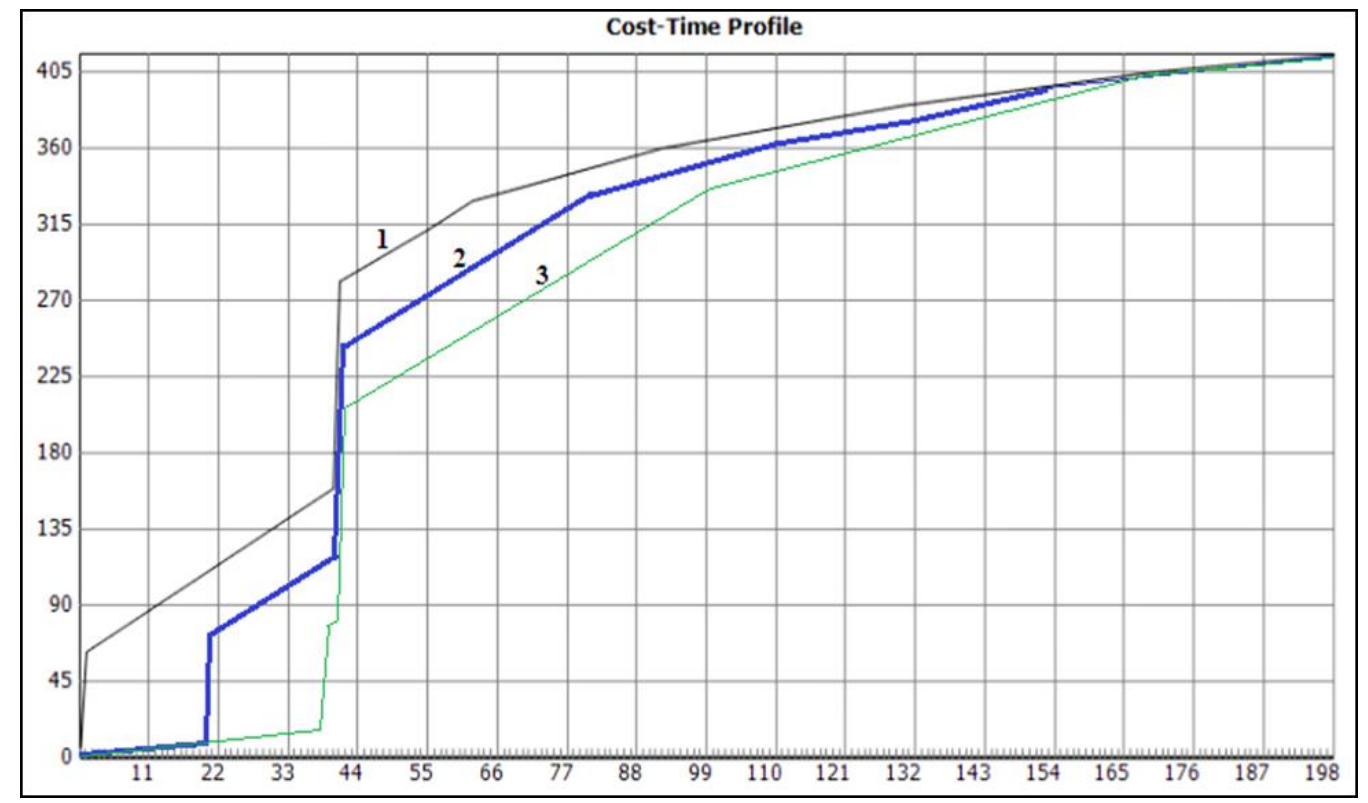

Fig. 3. Project cost-time profile / investment presentation for the cases 1, 2, and 3 
The influence of performing times of non-critical activities (always our planning decision) on the CTI value is the following:

$$
\frac{C T I_{1}}{C T I_{2}}=107.5 \% \quad \frac{C T I_{1}}{C T I_{3}}=116.3 \%
$$

The difference of more than $16 \%$ between the best and the worst result should not be overlooked. Even at very simple projects, we must tend to the implementation of JIT principles regarding the scheduling of all non-critical activities. Such actions also contribute to the lean project philosophy.

Optimal CTI3 means that we invest (locked-up capital) in the time of 25 days on average 219382 EUR daily. In the most unfavourable case 1 we have on average 255191 EUR invested. Money savings and reduced cost-time investments are extremely important in the crisis time and contribute to the effectiveness of the company.

\section{Coefficient of investment - comparison of all cases}

An illustration of equal, linear investment during the project duration is shown in Fig. 4. Diagonal line of costtime profile presents a reference, which can be used for further comparison of different cases.

$\mathrm{X}$-axis represents project duration time $(\mathrm{t})$, on the $\mathrm{y}$-axis the accumulated total costs are shown. The goal of project planning is linked with the reduction of the area under the cost curve, which means lower cost-time investment (CTI). Comparison of different cases is possible with the coefficient of investment (CI), described in eq. (3):

$C_{t}=\frac{2 \times C T I}{t \times C}$

Possible value of CI is inside the interval 0 to 2 . Real cases show that values below 1.5 are good, and values below 1 are excellent.

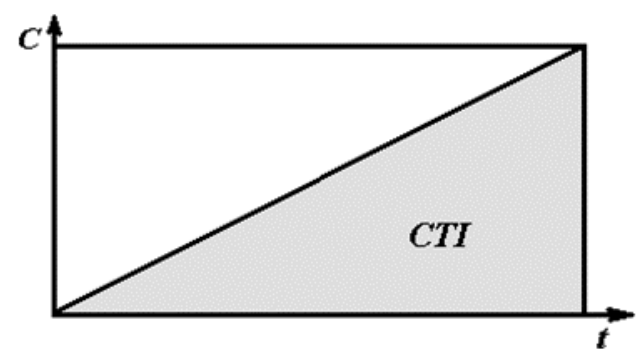

Fig. 4. Reference cost-time profile and basic form of cost-time investment CTI

\subsection{Calculation for the three compared project cases}

For the calculation, we use the CTI data for the cases:

$$
\begin{aligned}
& C_{I 1}=\frac{2 \times 6379780}{200 \times 41570}=1.53 \\
& C_{I 2}=\frac{2 \times 5932170}{200 \times 41570}=1.43 \\
& C_{I 3}=\frac{2 \times 5484560}{200 \times 41570}=1.32
\end{aligned}
$$

From the results, it is evident that case 2 and especially case 3 are advantageous regarding the project efficiency. Additionally this is the proof that project optimization can bring essential benefits during the execution and needed investments. This is extremely important for praxis.

\section{Conclusion}

Project success includes time, budget, quality, customer satisfaction etc. Project oriented companies very rarely use cost-time profile tools in their project evaluation activities.

The paper examines the impact of project cost accumulation over the time and cost-time investment for the selection of appropriate execution plan to increase the efficiency of projects.

We have dealt with a simple project to evaluate the impact of non-critical activities execution time periods to project's cost-time investment. These activities have a considerable influence to the amount of locked-up capital. Using slack for 
delay of such activities brings essential improvements, but we must be aware of all potential, associated risks and uncertainty. For the visualization of project cost accumulation, we have applied cost-time profile; we have used Cost Time Profiler software.

Project management is a very appropriate research field, because it combines activities and economical use of resources. Using the developed coefficient of investment enables correct comparison between different project plans. The use of cost-time profiles to analyse processes is a powerful tool to the process improvement methodology.

Our future work in the field of cost-time profiles will include more complex projects and detailed observation of all cost components to bring additional original contribution to the project field.

\section{References}

[1] A. M. Deif, A system model for green manufacturing, Advances in Production Engineering \& Management, 6 (2011) 1, 27-36.

[2] J. Pinto, Project management: achieving competitive advantage, Pearson Education, Upper Saddle River, 2007.

[3] R. K. Wysocki, Effective project management: Traditional, agile, extreme, Wiley Publishing, Indianapolis, 2009.

[4] J. M. Nicholas, H. Steyn, Project management for engineering, business and technology, Routledge, Oxon, 2012.

[5] R. Zhao, Simulation-based environmental cost analysis for work-in-process, International Journal of Simulation Modelling, 11 (2012) 4, 211-224.

[6] L. McLeod, B. Doolin, S. G. MacDonell, A perspective-based understanding of project success, Project Management Journal, 43 (2012) 5, 68-86.

[7] X. D. Lai, G.-D. Wu, J. G. Shi, H. M. Wang, Q. S. Kong, Project value-adding optimization of project-based supply chain under dynamic reputation incentives, International Journal of Simulation Modelling, 14 (2015) 1, 121-133.

[8] B. Buchmeister, Z. Kremljak, D. Gračanin, Introduction of a new performance measure for job shop scheduling, 18th International Research/Expert Conference TMT 2014, 449-452, Budapest, 2014.

[9] J. H. Fooks, Profiles for performance: total quality methods for reducing cycle time, Addison-Wesley, Reading, 1993.

[10] L. Rivera, Inter-Enterprise Cost-Time Profiling, PhD Dissertation, Virginia Polytechnic Institute and State University, Blacksburg, 2006.

[11] Z. Kremljak, I. Palcic, C. Kafol, Project evaluation using cost-time investment simulation, International Journal of Simulation Modelling, 13 (2014) 4, 447-457.

[12] D. Gracanin, B. Lalic, I. Beker, D. Lalic, B. Buchmeister, Cost-time profile simulation for job shop scheduling decisions, International Journal of Simulation Modelling, 12 (2013) 4, 213-224.

[13] D. Gracanin, B. Buchmeister, B. Lalic, Using cost-time profile for value stream optimization, Procedia Engineering, 69 (2014) 1225-1231.

[14] R. Shah, P. T. Ward, Lean manufacturing: context, practice bundles and performance, Journal of Operations Management, 21 (2003) 2, 129-149.

[15] L. Wilson, How to implement lean manufacturing, McGraw-Hill, New York, 2010.

[16] A. Haider, J. Mirza, An implementation of lean scheduling in a job shop environment, Advances in Production Engineering \& Management, 10 (2015) 1, 5-17.

[17] G.-D. Wu, Project-based supply chain cooperative incentive based on reciprocity preference, International Journal of Simulation Modelling, 13 (2014) 1, 102-115.

[18] L. Rivera, F. F. Chen, Measuring the impact of Lean tools on the cost-time investment of a product using costtime profiles, Robotics and Computer-Integrated Manufacturing, 23 (2007) 6, 684-689.

[19] S. M. Seyedhosseini, A. Ebrahimi-Taleghani, Using cost-time profile to estimate the product direct cost in multiproduction value stream, International Journal of Services and Operations Management, 18 (2014) 3, $233-257$. 